\title{
Spatiotemporal Variation of Irrigation Water Requirement in the China-Pakistan Economic Corridor
}

\section{Yaqi Li}

Chinese Academy of Sciences

\section{Yaning Chen}

Chinese Academy of Sciences

Weili Duan ( $\nabla$ duanweili@ms.xjb.ac.cn )

Chinese Academy of Sciences

\section{Mengzhu Cao}

Chinese Academy of Sciences

Jingxiu Qin

Chinese Academy of Sciences

\section{Research Article}

Keywords:

Posted Date: February 24th, 2022

DOI: https://doi.org/10.21203/rs.3.rs-1288562/v1

License: (c) (i) This work is licensed under a Creative Commons Attribution 4.0 International License. Read Full License 


\section{Abstract}

Agricultural irrigation consumes most of the fresh water in the China-Pakistan Economic Corridor (CPEC), directly affecting water resource management and allocation. Irrigation water demand is an important part of regional water resources management. Herein, we analyzed the spatiotemporal variation of irrigation water requirement, irrigation demand index (IDI), and proposed regional optimization of irrigation water use based on the Bayesian probability network. The results showed that: (1) The IDI in the study area increased slightly (trend slope $=0.028 \mathrm{a}^{-1}$ ) as the effective precipitation increased by $63 \%$ during this period, and total irrigation water requirement (IR) decreased from $277.61 \mathrm{~km}^{3}$ in 2000 to $240 \mathrm{~km}^{3}$ in 2015 (2) The highest crop IDI was exhibited by cotton, followed by maize and wheat. (3) According to the comprehensive scenario analysis, improving the crop planting structure (by moderately increasing the planting proportion of maize in the CPEC) is conducive to improving regional water and food security by enhancing grain yield (+9\%), reducing the malnourished population (low state $+7.2 \%$ ), and bolstering water-saving irrigation technology as well as water conveyance systems in Pakistan. Our results pave the way toward sustainable water resource utilization management in the CPEC.

\section{Introduction}

The China-Pakistan Economic Corridor (CPEC) is located between the Kashgar Prefecture (KP) in the Xinjiang Province of China and Pakistan and its surrounding areas. The CPEC currently represents an important part of the Belt and Road Initiative (BRI). Therefore, it is essential for the promotion of regional and transregional economic and trade integration between South, Central, East, and West Asia ${ }^{1}$. Like in China, agriculture plays an important role in national economic growth of Pakistan and represents one of the main driving forces of its national economic growth ${ }^{2}$. A survey revealed that the economic growth of Pakistan fluctuated due to agricultural problems, owing to such variability, the economic growth and the total amount of production factors in Pakistan will likely slowdown in the near-future ${ }^{3}$. At the same time, the country still faces severe food security problems despite a significant increase in gross agricultural product (GAP). According to the Food and Agriculture Organization of the United Nations (FAO), the database showed that $>48 \%$ of the population in Pakistan is currently at risk of food insecurity.

Water resources are an important factor, limiting agriculture, while agricultural productivity and sustainability both largely depend on timely and adequate water supply ${ }^{4}$. Most sub-regions of the CPEC are located in arid and semi-arid areas, where water resources are scarce. Moreover, Pakistan is one of the poorest countries in the world in terms of water resources. The World Bank has previously indicated that the total water resources of Pakistan are 185.8 billion $\mathrm{m}^{3}$, with the level of water resources below the world and per capita level in China. According to statistical yearbook data, the agricultural water in Pakistan and Xinjiang accounted for $94 \%$ of the total freshwater resources in 2017, thereby, accounting for the largest proportion of the utilization of water resources. Furthermore, the continuous growth of population and agricultural production has further exacerbated the regional demand for water resources in the region ${ }^{5}$. Hence, the supply and storage of water resources are a major challenge at the international and regional levels ${ }^{6}$. It is currently considered that the extent and productivity of both irrigated and rainfed agriculture are expected to change.

The use of irrigation water is essential for improving the productivity of existing farmland ${ }^{7}$, and is also pivotal for determining agricultural irrigation water consumption requirements. Specifically, the water consumption for crop growth and development depends on the meteorological conditions, crop types, and crop planting area. The Penman-Monteith (PM) equation has been applied for estimating crop reference evapotranspiration when calculating crop water requirements. However, more meteorological data are required for its broad-scale applications. Given the socio-economic and other regionspecific challenges, it is difficult to obtain long-term meteorological data of high quality in Pakistan. Owing to this, we propose to use the PM simplified formula from Hargreaves-Samani $(\mathrm{HS})^{8}$ to calculate crop reference evapotranspiration. Previous studies have shown that this formula can be efficiently applied in arid and semi-arid areas including the CPEC. Specifically, Syperreek et al. ${ }^{9}$ and Borges et al. ${ }^{10}$ have already used the HS and PM formulae to quantify potential evapotranspiration (PET) in arid and tropical areas of Brazil. Their results revealed that the HS formula is well optimized for 
this climate zone. Furthermore, Maeda et al. ${ }^{11}$ conducted research in Kenya and verified the results of the simplified formula with FAO Penman-Monteith (PM-FAO) as the standard. They confirmed that the HS is the most suitable simplified formula for calculating PET in such regions, when meteorological data are scanty. Moreover, Er-Raki et al. ${ }^{12}$ concluded that HS is even more optimized, than the Priestley-Taylor (PT) and Makkink (MAK) formulae for calculating PET in the semi-arid areas of I Mexico. López-Urrea et al. ${ }^{13}$ have compared seven formulae including PM-FAO, FAO-24 Penman (I) and (II) approaches, Blaney-Criddle (BC) for calculating PET in the semi-arid climate of Spain versus experimental results. They have concluded that the HS formula was only second after the PM-FAO in terms of accuracy. Furthermore, Wei ${ }^{14}$ have compared the computational accuracy of five algorithms including HS, PT, Irmak-Allen (IA), MAK, and Penman-van Bavel (PVB). They have addressed to the PM calculation as the standard and showed that HS is the optimal algorithm for both the upper and lower reaches of the Chelchen River basin in southern Xinjiang. Nazeer ${ }^{15}$ have compared the results of PET, calculated by PM, PMFAO, and HS, with the original PET from Class A pan in Pakistan. They found that HS was more reliable (coefficient of determination, $\mathrm{R}^{2}=0.96$ ) and simpler for application, compared with other alternative methods. Thus, when other climate parameters are missing or unreliable, this formula can be utilized as an alternative to PM-FAO. On this basis, we opted for the HS method for quantifying PET in the study area of the CPEC.

A Bayesian network is the approach for unravelling the uncertain knowledge expression and inference. It has demonstrated great prospects for integrating a series of knowledge sources and was deemed flexible to deal with uncertainty, caused by data scarcity and/or limited knowledge of the system from mathematical perspective ${ }^{16}$. Some studies have already used Bayesian networks in water resources management and other fields by mainly focusing on water quality ${ }^{17,18}$, groundwater $^{19}$, 20 , or irrigation water ${ }^{21,22}$. Previous studies on irrigation water requirements in the CPEC have mostly addressed to Pakistan or Xinjiang (Province of China) as the study area, thereby, focusing on the water demand of a single crop $23,24,25$, especially lacking in-depth analysis and research on regional overall irrigation water use. We argue that a Bayesian network can be applied as an effective method for addressing the above problems.

This study elucidated the irrigation water requirements of major crops (maize, wheat, and cotton) in the CPEC in the 20002015 period. To this end, we (1) analyzed the spatiotemporal variation characteristics of irrigation water requirement and irrigation demand index of main crops (maize, wheat, and cotton) in irrigated areas of the CPEC; (2) provided the scenario simulation results based on the Bayesian probability network; and (3) tailored the guidelines for more effective agricultural irrigation management measures in the CPEC.

\section{Results}

\section{Net irrigation water requirement and irrigation demand index}

The $I R_{\text {net }}$ of the three crops showed a downward trend from 2000 to 2015 . Figure 1 shows the averaged states of $I R_{\text {net }}$ for wheat, maize, and cotton in the CPEC during 2000-2015. We found that the spatial distribution of $\operatorname{IR}_{\text {net }}$ for the three crops was relatively consistent. Specifically, the spatial distribution revealed a decreasing trend from south to north except $I R_{\text {net }}$ in $K P$, which slightly increased (the trend slope is $0-1.5 \mathrm{~mm} \cdot \mathrm{a}^{-1}$ ). We identified that the annual $\mathrm{R}_{\text {net }}$ of the three crops was (in the descending order): cotton, maize, and wheat. Of them, the areas with high $\mathrm{IR}_{\mathrm{net}}$ for wheat were mainly clustered in the north of Sindh province, Pakistan with the trend slope of $-10-20 \mathrm{~mm} \cdot \mathrm{a}^{-1}$. The change in some areas was found to be significant $(0.01<p<0.05)$, while the lowest value of $I R_{n e t}$ for wheat was revealed in northern Punjab, Pakistan, and the KP irrigated area of Xinjiang $(<1,500 \mathrm{~mm})$. The $I_{\text {net }}$ in some areas of the KP exhibited an increasing trend during these years, with a trend slope of $0-1.5 \mathrm{~mm} \cdot \mathrm{a}^{-1}$ and an extremely significant change $(\mathrm{p}<0.01)$. Meanwhile, $\mathrm{IR}_{\text {net }}$ in the north of Punjab province was estimated to be $\sim 900-1,000 \mathrm{~mm}$ with the trend slope of $-40-50 \mathrm{~mm} \cdot \mathrm{a}^{-1}$. This finding indicates that the low value regional cluster (low $I R_{\text {net }}$ ) also signified the area with the strongest decreasing trend of $I_{\text {net }}$. The overall distribution of $\mathrm{IR}_{\text {net }}$ in maize was found to be similar to that of wheat. The high-value area was located in Sindh and south of Punjab 
province, where $\mathrm{IR}_{\text {net }}$ was $\sim 2,400 \mathrm{~mm}$ with the trend slope of $-10-20 \mathrm{~mm} \cdot \mathrm{a}^{-1}$. The low value cluster was mainly located in the north of Punjab province and KP, whereas the trend slope in some areas of the KP-irrigated area was $>0$, but the slope was small. The spatial distribution of the $\mathrm{IR}_{\text {net }}$ of cotton was also found to be similar to that of wheat. In general, the areas with high $I_{\text {net }}$ were mainly clustered in Sindh province and southern Punjab province of Pakistan. This spatial pattern can be explained by the strong drought in most parts of central and southern Pakistan.

In terms of IDI, as the irrigation efficiency is considered in formula (3), its partial result is $>1$. Like the spatial distributions of the averaged $I R_{\text {net }}$, the annual average IDI of the three crops was found to be cotton, maize, and wheat (in the descending order). This pattern was naturally driven by the spatial distribution of $\mathrm{ET}_{0}$. Besides the IDI of the central and northern parts of Punjab province (<1), the IDI of the three crops in other areas was greater than 1 (Fig. 2). Moreover, the change in the IDI of the three crops in these years was not significant $(p>0.5)$. Of them, the IDI of wheat and maize was $\sim 1.0-1.2$ in the middle of Punjab, 0.8-0.9 in the north, and 1.2-1.3 in other areas. The IDI of cotton was generally higher than that of wheat and maize. Besides the estimates of northern Punjab (1.1-1.2), it was found to be 1.2-1.3 in other regions, indicating a relatively high demand for irrigation. Furthermore, Supplementary Fig.S1 shows that the IDI of the three crops in the CPEC was relatively large, while the average annual IDI of the three crops varied and decreased, indicating that the overall irrigation demand of the region has slightly improved (the trend slope was $\sim 0.028 \mathrm{a}^{-1}$ ). Although the overall irrigation demand of the CPEC was slightly improved over the years, the current conditions of irrigation water resources in some areas are still undesirable. Nowadays, Sindh and Punjab are the main irrigated areas of Pakistan, while the water use in Punjab is becoming less sustainable. The movement toward sustainability was mainly impeded by the water use in the dry season of $\mathrm{Rabbi}^{26}$, which has exceeded the canal flow and the available amount of rainwater in Sindh province in the meantime. As a result, a severe deficit of the irrigation water is still present ${ }^{27}$.

\section{Total irrigation water requirement}

\section{Analysis on the change of irrigated agricultural land}

In the study period (2000 to 2015), the irrigated area of CPEC showed a slightly fluctuating upward trend (Supplementary Fig. S2a). The planting area of wheat was the most extensive, followed by cotton and maize. Supplementary Figure S2 (c) and (d) also illustrate that the planting proportion of crops has varied within the CPEC. The annual average planting proportions of wheat, maize, and cotton in Xinjiang (KP and Kizilsu Kirgiz Autonomous Prefecture (KKAP)) were estimated to be 0.40, 0.31 , and 0.44 , respectively. Thus, the planting proportions of the three crops were close to each other and relatively stable during the years. The sharp increase in the proportion of cotton planting in 2014 emerged mainly due to the government's statistical verification of cotton planting areas, including some non-agricultural production units. In Pakistan, the planting proportion of the crops has experienced only a little change during this period. The multi-year average planting coefficients of wheat, maize, and cotton were found to be $0.46,0.06$, and 0.16 , respectively. We revealed that wheat exhibited the largest proportion of all three crops and can be regarded as the most widely planted crop in Pakistan.

As seen from Supplementary Fig. S2(b), the change in the actual irrigated cultivated land area in the CPEC exhibited pronounced phased characteristics. In particular, there was a trend of continuous growth first. Then, the variability narrowed with an overall increase of $5,398 \mathrm{~km}^{2}$. From 2000 to 2010, the actual irrigated cultivated land area in the CPEC continued to increase, until reaching $20.3 \times 104 \mathrm{~km}^{2}$ in 2010 , which corresponds to the increase of $\sim 13,439 \mathrm{~km}^{2}$. Of them, the total irrigated cultivated land area of the KKAP and KP exhibited both fluctuations with a general increase. However, the overall fluctuation range was somewhat small during this period. The change in the actual irrigated cultivated land area in Pakistan is in line with that in the CPEC. This finding suggests that the change in the actual irrigated area in Pakistan played a key role in changing the irrigation land in the CPEC. The main driver of the change in actual irrigation land in Pakistan during these years could be related to the following surmise. We suggest that the food crisis broke out simultaneously under the background of the global economic crisis, which substantially affected the agricultural output value of Pakistan. Previous 
study has shown that the population growth and cross-border flow of rainwater in Pakistan not only offset the positive effects of grain production growth on food security, but also bolstered the import of wheat to supplement domestic supply 28 . Pakistan has already implemented a series of measures such as increasing the area of cultivated land to increase crop yield, for instance. From 2010 to 2013, the area of irrigated cultivated land in the CPEC has decreased and there are two possible drivers of this decrease. Possibly, severe floods in Pakistan, affected by extreme precipitation for many times from 2010 to 2012 damaged thousands of crops and $\sim 2 \times 10^{6} \mathrm{hm}^{2}$ of farmland in 2010 . This subsequently caused severe economic losses of 10 billion dollars $29,30,31$. Alternatively, some other scholars stated that the rapid expansion of cultivated land was influenced by policies in the early stage during this period. As a result, the cultivated land rapidly expanded, vegetation decreased, soil barren/land productivity declined, and some farmers ultimately abandoned their land for cultivation. This abandonment, in turn, induced a decrease in cultivated land area due to low economic efficiency ${ }^{32}$.

Analysis on changes of total irrigation water requirement of main crops

The changes in the IR of major crops during 2000-2015 are illustrated in Supplementary Fig. S3, that were obtained by multiplying the $\mathrm{IR}_{\mathrm{net}}$ of the three crops and their planting areas. In general, the IR of the three crops revealed a slight fluctuation decreasing trend with a reduction of $37.61 \mathrm{~km}^{3}$ and the annual average of $\sim 253.99 \mathrm{~km}^{3}$.

We estimated the average annual IR of the three crops in the CPEC to be $153.98 \mathrm{~km}^{3}$ for wheat, $24.73 \mathrm{~km}^{3}$ for maize and $75.28 \mathrm{~km}^{3}$ for cotton. These results are different from the $\mathrm{IR}_{\text {net }}$ distribution, which is mainly affected by the planting area of the crops. Currently, wheat is the most widely planted food crop in the CPEC, which serves as the main food crop for millions of people in Pakistan and the main source of heat intake. It accounts for the largest share of the total cultivated and produced agricultural area by attributing for $9.1 \%$ of the agricultural added value and $1.7 \%$ of Pakistan's GDP ${ }^{33}$. Although the annual average estimates $I R_{\text {net }}$ and IDI were found to be lower than those of other crops, wheat is still the crop with the highest IR. We found that the interannual variation trend of IR of wheat was relatively consistent with the sum of the IR of the three crops. We also found that the change in IR of wheat significantly affected the utilization of irrigation water resources. Moreover, cotton was characterized by the least planting area of the three crops, but its IR was higher than that of maize. This is mainly because cotton is a cash crop with high water consumption, and its $I_{\text {net }}$ is largest among the three crops. Previous study has shown that the increase in crop water demand, caused by the growth of air temperature and the change in crop planting structure in southern Xinjiang triggered an overall upward trend of irrigation water demand. The change in planting structure, especially the expansion of cotton planting area, was the main driver of the significant spatiotemporal increase in the irrigation water requirement ${ }^{34}$. As seen, cotton, as a typical cash crop, produced a significant impact on regional water resources in the CPEC. In general, balancing the planting proportion of food crops and cash crops is pivotal for regional economic growth and water and food security, which emphasizes the rationalization of regional crop planting structure.

\section{Analysis on irrigation water use based on Bayesian network Sensitivity analysis of key variables}

The sensitivity analysis can unravel the extent to which the posterior probability distribution has changed, given the probability distribution of the other nodes in the network. This analysis revealed that $\mathrm{MI}$ and VB exhibited a relatively consistent trend. In general, the greater the MI, the greater the VB, the higher the sensitivity of the target variable. As a result, the impact on the target node decreases when the intermediate variables between the node and the target node increase (Supplementary Fig. S5). The sensitivity analysis based on evaluation method was further conducted because the applicability of the model can be verified through the evaluation versus factual evidence. In this study, five important nodes, reflecting regional irrigation water use and security of water and food were selected as target variables for sensitivity analysis based on the Netica software. Taking "IR of main grain crops" and "Effective irrigated area" as examples, the IR is the product of crop planting area and $I R_{\text {net }}$ of corresponding crops. As a result, it is most affected by crop planting area and

Page 5/23 
$I R_{\text {net }}$. The statistical yearbook data can be used for assessing the planting area of main food crops in the CPEC $(12,751.9$ $\mathrm{km}^{2}$ ) and the annual actual irrigated area $\left(19,328.2 \mathrm{~km}^{2}\right)$ in the past two decades. We found that the planting area of food crops occupied the largest proportion in the irrigated area and significantly affected it. The above sensitivity analysis results are notably consistent with the previously reported evidences. At the same time, economic factors, grain yield, and population; all significantly affected regional food security, according to the sensitivity analysis results of "Undernourished population" which is consistent with previous findings ${ }^{35}$. However, since we have not considered such major influencing factors as education level, some nodes were less sensitive to other nodes or could not reflect strong causal relationships.

\section{Response of target variables to scenario variables under different scenarios}

The constructed Bayesian network can be utilized for analyzing the relative possibility of different state changes of target variables under different management and planting situations. The change in each state probability of the output variable can be predicted by adjusting the state of the input variable. One of the main ideas of this study was to aim at optimizing irrigation management measures and adjusting crop planting structure to improve the current situation of water and grain security, and the degree of regional cooperation. To this end, we also analyzed the degree of benefit of target variables under different scenarios. On this basis, this study also explored the changes in target variables when each scenario variable is utilized as a scenario (Table 1). 
Table 1

Responses of target variables to scenario variables in different scenarios.

\begin{tabular}{|c|c|c|c|c|c|c|c|c|c|c|c|c|c|c|}
\hline \multirow[t]{2}{*}{ Target node } & \multicolumn{14}{|c|}{ Nodes for scenario setting } \\
\hline & SA & $\mathrm{FL}$ & $\mathrm{FH}$ & WL & WH & IW & LCL & $\mathrm{LCH}$ & LF & LW & LM & LR & LSH & LSL \\
\hline $\begin{array}{l}\text { Major cash crops } \\
\text { acreage (high) }\end{array}$ & $\begin{array}{l}+ \\
1.2\end{array}$ & & & & & $\stackrel{+}{0.2}$ & & & & & & & & \\
\hline $\begin{array}{l}\text { Output of major } \\
\text { grain crops(high) }\end{array}$ & $\begin{array}{l}+ \\
0.2\end{array}$ & $\stackrel{+}{2.5}$ & $\begin{array}{l}+ \\
5.6\end{array}$ & & & $\begin{array}{l}+ \\
0.1\end{array}$ & & & $\begin{array}{l}+ \\
5.5\end{array}$ & $\begin{array}{l}+ \\
5.7\end{array}$ & +9 & $\begin{array}{l}+ \\
4.4\end{array}$ & -0.2 & -0.1 \\
\hline $\begin{array}{l}\text { Major grain crops } \\
\text { acreage (high) }\end{array}$ & ++ & & & & & & & & & & & & & \\
\hline $\begin{array}{l}\text { Output of major } \\
\text { cash crops(high) }\end{array}$ & & $\stackrel{+}{2.8}$ & $\begin{array}{l}+ \\
8.7\end{array}$ & & & & -1.3 & $\begin{array}{l}+ \\
1.6\end{array}$ & & & & & $\begin{array}{l}+ \\
10.7\end{array}$ & $\stackrel{+}{4.5}$ \\
\hline $\begin{array}{l}\text { Undernourished } \\
\text { population(low) }\end{array}$ & $\begin{array}{l}+ \\
2.1\end{array}$ & & -0.2 & & & & -0.2 & -0.4 & & $\begin{array}{l}+ \\
0.5\end{array}$ & $\begin{array}{l}+ \\
7.2\end{array}$ & $\begin{array}{l}+ \\
0.7\end{array}$ & & -0.1 \\
\hline $\begin{array}{l}\text { Undernourished } \\
\text { population(high) }\end{array}$ & & & & & & & & & & & & & $\begin{array}{l}+ \\
0.4\end{array}$ & $\stackrel{+}{0.2}$ \\
\hline Arable land(high) & $\stackrel{+}{17}$ & & & & & & & & & & & & & \\
\hline GAP (high) & & & $\begin{array}{l}+ \\
1.4\end{array}$ & & & & -0.2 & $\begin{array}{l}+ \\
0.1\end{array}$ & $\stackrel{+}{2.6}$ & $\stackrel{+}{2.5}$ & +3 & $\begin{array}{l}+ \\
2.2\end{array}$ & $\begin{array}{l}+ \\
0.3\end{array}$ & $\begin{array}{l}+ \\
0.1\end{array}$ \\
\hline $\begin{array}{l}\text { Agricultural water } \\
\text { consumption(low) }\end{array}$ & & $\begin{array}{l}+ \\
0.1\end{array}$ & $\begin{array}{l}+ \\
0.1\end{array}$ & & & & & & & & & & & \\
\hline $\begin{array}{l}\text { Proportion of } \\
\text { population with } \\
\text { safe drinking } \\
\text { water(high) }\end{array}$ & & -4.9 & -4.8 & $\begin{array}{l}+ \\
0.3\end{array}$ & -1.4 & $\begin{array}{l}+ \\
0.3\end{array}$ & & & -0.8 & -0.8 & -0.8 & -0.8 & & \\
\hline Total IR (low) & & $\begin{array}{l}+ \\
0.4\end{array}$ & $\stackrel{+}{0.9}$ & -1.4 & $\begin{array}{l}+ \\
0.7\end{array}$ & & & & -0.2 & & & & & \\
\hline $\begin{array}{l}\text { Total } I_{\text {net }} \text { of } \\
\text { major cash } \\
\text { crops(low) }\end{array}$ & & & & & & & -5.6 & -17 & & & & & -9.6 & -4.7 \\
\hline $\begin{array}{l}\text { Total } I_{\text {net }} \text { of } \\
\text { major cash } \\
\text { crops(high) }\end{array}$ & & & & & & & & $\begin{array}{l}+ \\
8.1\end{array}$ & & & & & $\begin{array}{l}+ \\
4.1\end{array}$ & \\
\hline $\begin{array}{l}\text { Total } I_{\text {net }} \text { of } \\
\text { major grain } \\
\text { crops(high) }\end{array}$ & & & & & & & & & $\begin{array}{l}+ \\
18.2\end{array}$ & $\stackrel{+}{10.5}$ & +9 & $\begin{array}{l}+ \\
10.3\end{array}$ & & \\
\hline $\begin{array}{l}\text { Total } I_{\text {net }} \text { of } \\
\text { major grain } \\
\text { crops(low) }\end{array}$ & & & & & $\stackrel{+}{27}$ & -0.2 & & & & -7.6 & -6.2 & -7.6 & & \\
\hline $\begin{array}{l}\text { Groundwater } \\
\text { usage(low) }\end{array}$ & & & & +8 & & & & & & & & & & \\
\hline
\end{tabular}

Note: SA: saline-alkali land area (low); FL: quantity of chemical fertilizer (low); FH: quantity of chemical fertilizer (high); WL: number of tube wells (low); WH: number of tube wells (high); IW: total IR (low); LCL: cotton acreage (low); LCH: cotton acreage (high); LF: major grain crop acreage (high); LW: wheat acreage (high); LM: maize acreage (high); LR: rice acreage (high); LSH: sugarcane acreage (high); LSL: sugarcane acreage (low). The "high" and "low" indicate the highest or lowest level of each node after discretization, respectively. The values in the table show the change in the percentage probability values of the specific states of the response nodes on the left after the "high" or "low" states of the upper scenario variables are determined. 


\begin{tabular}{lllllllllllllllllll}
\hline Target node & \multicolumn{1}{l}{ Nodes for scenario setting } & & SA & FL & FH & WL & WH & IW & LCL & LCH & LF & LW & LM & LR & LSH & LSL
\end{tabular}

Groundwater

usage(low)

Applying quantity

of chemical

fertilizer(low)

$+$

0.3

Note: SA: saline-alkali land area (low); FL: quantity of chemical fertilizer (low); FH: quantity of chemical fertilizer (high); WL: number of tube wells (low); WH: number of tube wells (high); IW: total IR (low); LCL: cotton acreage (low); LCH: cotton acreage (high); LF: major grain crop acreage (high); LW: wheat acreage (high); LM: maize acreage (high); LR: rice acreage (high); LSH: sugarcane acreage (high); LSL: sugarcane acreage (low). The "high" and "low" indicate the highest or lowest level of each node after discretization, respectively. The values in the table show the change in the percentage probability values of the specific states of the response nodes on the left after the "high" or "low" states of the upper scenario variables are determined.

As shown in Table 1, the cultivated land area can be effectively increased (+ 17\%) by reducing the area of saline alkali land, compared with the actual situation. Table 1 also shows that, compared with reducing chemical fertilizer application, increasing chemical fertilizer application within a certain range can effectively increase the yield of grain crops $(+5.6 \%)$ and cash crops $(+8.7 \%)$ in terms of chemical fertilizer application. However, the increasing chemical fertilizer application would have a negative impact on safe water use $(-4.8 \%)$. We argue that the increasing of the number of tube wells can somewhat help improving the irrigation efficiency and easing irrigation water requirements (low state $+27 \%$ ). However, it also poses a threat to drinking water health $(-1.4 \%)$, which requires urgent search for safer, more effective farming and irrigation method to improve irrigation efficiency for the region as a whole, especially for Pakistan.

In terms of crop planting structure, this study mainly analyzed three crops: wheat, maize and rice among the food crops. The results revealed that of the three main food crops, increasing the planting area of regional maize under the current situation is more efficient for improving the overall water and food security conditions in the CPEC. In a certain range, increasing the planting area of maize can more effectively enhance grain yield $(+9 \%)$, reduce the malnourished population (low state + $7.2 \%)$, increase the GAP (+3\%). Its corresponding increase in IR (+9\%) was less than that of the other two crops (wheat + $10.5 \%$, rice $+10.3 \%$ ), and increasing the output of major grain crops was greater than that of the other two crops (wheat + $5.7 \%$, rice $+4.4 \%$ ). Of cash crops, this study mainly analyzed cotton and sugarcane and Pakistan is the fifth largest sugarcane planting country in the world, while Xinjiang is not a major producer of this crop. Therefore, Pakistan was mainly analyzed in terms of the planting structure of this crop. In the two crops of sugarcane and cotton, increasing a certain sugarcane planting area is more efficient for increasing the yield of cash crops $(+10.7 \%)$, while the demand for IR is relatively small $(+4.1 \%)$. Fundamentally, cotton is an extremely important cash crop for the CPEC. The cotton area of Xinjiang is the largest cotton region in China, and 63 of the 86 counties in Xinjiang are perennial cotton plantations. Cotton also significantly affects the agricultural economy of Pakistan by accounting for $8.2 \%$ of the national agricultural added value and for $\sim 3.2 \%$ of GDP, about two-thirds of the country's export revenue comes from cotton and textiles ${ }^{24}$. However, as a crop with high water consumption, increasing its planting area also induces a significant increase (8.1\%) in the IR of cash crops and affects the planting of food crops as well as regional food security to some extent. Furthermore, study 
demonstrated that a further expansion of the planting area had a negative impact on the development of the national economy in Xinjiang under the current high level of cotton-sown area and yield per unit area in Xinjiang ${ }^{36}$.

\section{Discussion}

Effective precipitation $\left(P_{e}\right)$ represents the replenishment of precipitation into irrigation, which is an important factor affecting the change of $I R_{n e t}$. The studies showed that the changes of precipitation and atmospheric $\mathrm{CO}_{2}$ concentration under the background of climate change may be the main factors controlling the temporal and spatial changes of $I R_{n e t} 37,38$. The increase of precipitation may directly lead to the decreasing trend of $I_{n}{ }_{n e t}{ }^{39}$. The increase of $P_{e}$ may have a certain impact on the decrease of irrigation water consumption in the CPEC. As showed in Fig. 3, the $\mathbb{I R}_{\text {net }}$ of the three crops decreased by $21 \%$, as the annual $P_{e}$ in irrigated area of the CPEC increases by $63 \%$ from 2000 to 2015 . At the same time, the $P_{e}$ of the main growing period of major crops (April to August) in irrigated area of the CPEC increases by $22 \%$ during this period. Noted that the distribution of precipitation in growing season has a significant impact on the distribution of irrigation time, optimizing irrigation strategy according to different precipitation conditions will be an effective practice of crop production and water saving ${ }^{40}$. In addition, there are spatial differences in the average annual $P_{e}$ of irrigated areas in the CPEC (Fig. 4). In Pakistan, the overall performance of $\mathrm{P}_{\mathrm{e}}$ increased, while $\mathrm{P}_{\mathrm{e}}$ in the KP-irrigated area revealed a weak decreasing trend with a trend slope of $\sim-0.9 \mathrm{~mm} \cdot \mathrm{a}^{-1}$ identified and the decreasing trend of $\mathrm{IR}_{\text {net }}$ in $\mathrm{KP}$ - irrigation area is also accordingly slower than that in Pakistan as a whole during these years. It can be deduced that the change in this type of precipitation has a certain correlation with altitude and terrain ${ }^{41}$ and $I R_{\text {net }}$ of maize and wheat is more affected by crop evapotranspiration in arid inland areas ${ }^{42}$.

Notably, the change of crop $\mathbb{I R}_{\text {net }}$ is not determined by any single climatic factor, such as the increase of temperature and $\mathrm{CO}_{2}$ concentration may lead to the decrease of stomatal conductivity and affect crop transpiration, so as to improve crop water efficiency and reduce $\mathrm{IR}_{\text {net }} 43,44,45$. Furthermore, the increase of precipitation contributes to reducing the pressure of regional irrigation water consumption to a certain extent, while improving irrigation technologies and conveyance systems have larger water saving potential ${ }^{46}$.

The shortage of water resources is an acute challenge, hampering the sustainable development of agriculture in Pakistan. Some studies have shown that Pakistan would become a water-scarce country by $2025^{47}$. The sixth population census of Pakistan in 2017 indicated that the population of Pakistan reached 278 million in 2017, which is nearly twofold, compared with the fifth population census of 1998 (an average annual population growth rate $=2.40 \%$ ). Due to the increase in population, the gap between the supply and demand of water resources is increasing, thereby, exacerbating the conflicts, caused by water resource disputes between provinces and the international community ${ }^{48}$. Increasing population pressure further underlines the importance of protecting and managing scarce resources. Thus, the development of water-saving agriculture is an inevitable measure for developing the agriculture in arid areas. Furthermore, future climate change scenarios indicated that the available water and agricultural water demand in the CPEC may increase given the increase in temperature ${ }^{49,50}$. To efficiently mitigate future climate change, it is pivotal to take corresponding water-saving irrigation measures and to adjust crop planting structure for protecting oasis ecosystems and for meeting residents' needs.

In Pakistan, nearly all soils are deficient in nitrogen, 80-90\% phosphorus, and $30 \%$ potassium ${ }^{51}$. In fact, the scenario analysis results we showed, indicated that an increase in a certain range can increase crop yield, compared with reducing the amount of chemical fertilizer. However, such increase has a negative impact on the environment. Furthermore, farmers use more fertilizers to increase yields, thereby, consuming more energy to operate modern agricultural techniques for meeting food demand ${ }^{52}$. Meanwhile, energy and fertilizer consumption intensify agricultural carbon emissions, thereby, affecting climate and natural resources and indirectly reducing agricultural output value $e^{53,54}$. Notably, the use of tube wells in Pakistan has triggered exactly the same problem. The scenario analysis suggested that increasing the number of tube wells 
can help improving the irrigation efficiency and somewhat reducing IR. Nevertheless, it will still pose a threat to the health of drinking water. As shown in Supplementary Fig. S6, the number of tube wells in Pakistan has significantly increased since 2000 (increase $=111 \%$ in $2000-2019$ ). Previous studies unraveled the human health risk increases in some parts of Pakistan, driven by the tube well pumping. As a result, the arsenic concentration in drinking water in the Punjab province of Pakistan exceeds the World Health Organization standard in all cases ${ }^{55}$. Moreover, the irrigation with inferior pipe well water will also lead to secondary salinization of cultivated land ${ }^{56}$. Namely, $70 \%$ of tube wells of the Indus Basin pump sodic or saline-sodic water, of which $2.3 \mathrm{Mha}$ of land has become sodic/saline ${ }^{57}$. It further highlights the urgent necessity to implement safer, more effective farming and irrigation methods to improve irrigation efficiency in Pakistan. Being affected by climate and numerous other factors, long-term traditional farming, soil salinization in the irrigated area of the CPEC is currently severe. For Pakistan, large-scale land reclamation, based on population growth, coupled with unscientific farming and irrigation, has led to greater salinization and a vicious circle has been formed as a result. Nowadays, the Pakistan's agriculture has entered the unsustainable path, mainly due to the degradation of land and water resources and due to the extensive use of inorganic inputs and inefficient irrigation water use ${ }^{58}$. At the same time, the main irrigated area in $\mathrm{KP}$, Xinjiang, the area of saline alkali land in the KP river basin is $86,000 \mathrm{hm}^{2}$ (e.g., accounting for $45 \%$ of the basin area) and the majority of the years are more than $60 \%$ according to the Xinjiang Statistical Yearbook. Today, the mitigation of soil degradation and soil salinization are both urgently required. Also, there is an urgent need to improve agricultural productivity, including improving the quality of soil salinization, crop seeds, fertilizers, pesticides, and the use of modern agricultural technologies.

Furthermore, using wheat as the crop with the largest planting area in the CPEC as an example. The drip irrigation technology of wheat in Xinjiang began to be tested and popularized in 2008. By 2017, the unit yield of wheat in Xinjiang increased from $4947 \mathrm{~kg} / \mathrm{ha}$ in 2008 to more than $8995 \mathrm{~kg} / \mathrm{ha}$, the unit yield of wheat in KP irrigated area in 2017 also reached $6049 \mathrm{~kg} / \mathrm{ha}$, while the unit yield of wheat in Pakistan in 2017 was only $2974 \mathrm{~kg} / \mathrm{ha}$ according to the data of Pakistan Yearbook. It fully reflects the great impact of scientific and effective irrigation agricultural technology on crop yield. It also emphasizes the importance of agricultural cooperation in the CPEC. Besides the internal coordination and optimization of Xinjiang and Pakistan (respectively), it is also very important to strengthen the cooperation between the two subregions for the prominent contradictions in the "Water-Energy-Food" relationship and the more macroscopic "WaterEnergy-Food-Ecology" nexus for the future sustainable development of the region. For instance, it is expected to gradually improve regional water and grain security by strengthening exchanges in agriculture, industrial technology, and other aspects between China and Pakistan, to enhance the utilization capacity of hydropower, to improve the efficiency of irrigation systems, and to bolster the upgrading of industrial structures.

The determination of irrigation water requirements of various important grain and cash crops in the CPEC can lay a foundation for precise estimation of irrigation water use. Due to the differences in research period and research area, it is challenging to compare the results of this study with previous research results in details, The obtained spatial distribution of $I R_{n e t}$ of wheat and cotton agree well with the previous studies, conducted in Pakistan ${ }^{24,25}$ and the KP-irrigated area of Xinjiang ${ }^{23}$. Moreover, our study analyzed the regional irrigation water use situation by using a Bayesian network, which applies a probability measure to enhance the measurement of uncertainty and relatively reduce the complexity of the model compared with the coupling modeling and the traditional water resources utilization optimization method ${ }^{59,60}$.

We also discussed the improvements from the two following two aspects. First, from $\mathbb{R}_{\text {net }}$ perspective, most previous studies have used $\mathrm{PM}$ to calculate $\mathrm{ET}_{0}{ }^{61,62}$. The estimated change from their studies was somewhat less sensitive to temperature compared to the HS Eq. $6^{3}$. Moreover, some researchers have recently developed a soil water balance simulation model to estimate $\mathrm{IR}_{\text {net }}{ }^{64}$. With the growing corpus of the relevant studies and the steadily improved data availability, the method for calculating $\mathrm{ET}_{0}$ will be more refined and accurate. Notably, $\mathrm{HS}$ is particularly applicable for the CPEC, other methods can be used in future if enough meteorological data would be available to quantify $\mathrm{ET}_{0}$. Moreover, the natural supply of agricultural water in Pakistan originates not only from rainfall, but also partly originates from ice melt water ${ }^{65}$. However, the calculation 
of $\mathrm{IR}_{\text {net }}$ mainly considers precipitation currently, while snow melt water was not considered. A Bayesian probability network

may unravel some hidden correlation patterns, previously unreported significant changes of the population, unknown climate and/or economic development of the basin in the future. However, the lack of prediction ability of new changes in the relationship would still limit the prediction ability of the network. Thus far, it is challenging to evaluate the factors, not included in the Bayesian networks, such as the popularity of advanced drip irrigation systems ${ }^{66}$.

\section{Methods}

\section{Study area}

The CPEC is located in the northwest of the South Asian subcontinent, between $24^{\circ} \mathrm{N}-40^{\circ} \mathrm{N}$ and $60^{\circ} \mathrm{E}-80^{\circ} \mathrm{E}$. It stretches from the Kashgar Prefecture (KP) of the Xinjiang province (China) in the north until the Gwadar Port (southern Pakistan). Its total length is $3,000 \mathrm{~km}$ and its total area is $927,597 \mathrm{~km}^{2}$. The CPEC's terrain is high in the northeast and low in the southwest. Most of the CPEC is covered by arid and semi-arid areas, whereas the east is greatly affected by the South Asian monsoon, with prominent dry and wet seasons. This region is highly sensitive to climate change ${ }^{67}$. Irrigation land in the study area is mainly distributed in the Sindh and Punjab provinces of Pakistan and KP of Xinjiang, China (Fig. 5). Note that KP is characterized by a temperate continental climate, while Sindh and Punjab in Pakistan are located in tropical desert and tropical monsoon climates, respectively. The main food crops in the irrigated area of the CPEC are mainly wheat, maize and rice, while the economic crops are mainly cotton in the CPEC and sugarcane in Pakistan.

\section{Data sources}

We used the daily resolution meteorological dataset for the CPEC from 1961 to $2015^{68}$. The dataset was composed of the observations from 65 near-ground meteorological stations in the CPEC and its surrounding areas. The final data were retrieved by using the Digital Elevation Model (DEM) from the region as the covariate, with a spatial resolution of $0.25^{\circ} \times$ $0.25^{\circ}$. The final resolution was achieved by spatial interpolation, performed in the ANUSPLIN (Australian National University Spline) software. This study used the following meteorological parameters (with daily resolution): maximum temperature, minimum temperature, and precipitation from 2000 to 2015.

In addition, other natural and socio-economic data such as water resources and food were mainly obtained from the Xinjiang Statistical Yearbook, Pakistan Statistical Yearbook, Pakistan Bureau of Statistics, the Economic Survey of Pakistan, the FAO Database (http://www.fao.org/faostat/zh/\#data), and the World Bank Database (https://data.worldbank.org.cn/). The specific data sources are summarized in Supplementary Table S1.

\section{Methodology}

The main framework and the methods used in this study are shown in Fig. 6. Note that the methods for analyzing the spatiotemporal characteristics of regional irrigation water requirements and irrigation water use are described in this section.

\section{Quantifying the irrigation water requirement}

\section{Quantifying the crop water requirement}

The reference evapotranspiration ( $\mathrm{ET}_{0}$ ) of crops was quantified by using the Hargreaves-Samani method. $\mathrm{ET}_{0}$ was calculated by using atmospheric top-level radiation $\left(R_{a}\right)$ instead of solar radiation $\left(R_{s}\right)$ in this study. The calculation formula is as follows:

$$
E T_{0}=0.408 C R_{a}\left(T_{\max }-T_{\min }\right)^{E} \cdot\left(\frac{T_{\max }+T_{\min }}{2}+T\right)
$$

where $R_{a}$ is the atmospheric top-level radiation $\left[M J /\left(m^{2} \cdot d\right)\right]$, which can be calculated from the daily ordinal number and geographical latitude, $\mathrm{T}_{\max }$ is the daily maximum temperature $\left({ }^{\circ} \mathrm{C}\right), \mathrm{T}_{\min }$ is the daily minimum temperature $\left({ }^{\circ} \mathrm{C}\right)$, and $\mathrm{C}, \mathrm{E}$, 
and $T$ represent the three parameters of the formula, respectively. They equal $2.3 \times 10^{-3}, 0.5$, and 17.8 , respectively.

The crop water requirement $\left(\mathrm{ET}_{\mathrm{c}}, \mathrm{mm}\right)$ was calculated by using the crop coefficient and $\mathrm{ET}_{0}$ :

$$
E T_{c}=K_{c} \times E T_{0}
$$

where $\mathrm{K}_{\mathrm{C}}$ is the crop coefficient. The crop coefficient refers to the estimates, reported in previous studies ${ }^{23,69,70,71}$.

\section{Calculating the net irrigation water requirement}

The net irrigation water requirement $\left(\mathrm{IR}_{\mathrm{net}}, \mathrm{mm}\right)$ expresses the unit water volume of crop growth dependent on irrigation in the CPEC from 2000 to 2015. according to the FAO recommendations the calculation of $I_{\text {net }}$ is as follows:

$$
I R_{n e t}=\frac{E T_{c}-P_{e}}{I_{e}}
$$

where $\mathrm{I}_{\mathrm{e}}$ is the irrigation efficiency, which expresses the ratio of the irrigation water used by crops to the actual extracted water. According to previous studies ${ }^{72,73}$, the overall irrigation efficiency in Pakistan and Xinjiang Province is $\sim 0.7$. $P_{e}$ is the effective precipitation, which reflects the rainfall transferred to soil moisture. In this study, we used the USDA (Unites States Department of Agriculture) method to calculate $\mathrm{P}_{\mathrm{e}}$ :

$$
\begin{aligned}
& P_{e}= \\
& \quad(P<250 \mathrm{~mm}) \\
& \quad(P \geq 250 \mathrm{~mm})
\end{aligned}
$$

where $\mathrm{P}$ is monthly precipitation $(\mathrm{mm})$.

\section{Calculating the irrigation demand index}

Irrigation demand index (IDI) refers to the proportion of net irrigation water requirement to crop water requirement reflecting the dependence of crop growth on irrigation. The calculation formula is as follows:

$$
I D I=\left\{\begin{array}{lr}
0 & E T_{c} \leq P_{e} \\
\frac{I R_{n e t}}{E T_{c}} & E T_{c}>P_{e}
\end{array}\right.
$$

\section{Calculating the total irrigation water requirement of crops}

$\mathrm{R}_{\text {net }}(\mathrm{mm})$ reflects the irrigation water required per unit area. We utilized the concept of total irrigation water requirement (IR) to reflect the total amount of irrigation water. The IR $\left(\mathrm{km}^{3}\right)$ is equal to the product of the crop planting area and IR $\mathrm{R}_{\text {net }}$, which reflects the volume of water.

\section{Analysis on irrigation water use based on Bayesian probability network}

\section{Bayesian network}

The Bayesian network is a directed acyclic graph model combining probability, statistics, and graph theory. In terms of model evaluation and validation, sensitivity analysis has been widely deemed to be more effective in evaluating model

performance $74,75,76$. Hence, the sensitivity analysis was applied to evaluate the sensitivity of the Bayesian network output variables to input variables. "Mutual information" (MI) based on entropy reduction and "Variance of Belief" (VB) based on 
variance reduction have been used as sensitivity analysis indicators for the Bayesian network model evaluation ${ }^{77}$. The calculation formulas are as follows:

$$
M I=H(Q)-H(Q \mid F)=\sum_{q} \sum_{f} p(q, f) \log _{2}\left(\frac{p(q, f)}{P(q) P(f)}\right)
$$

$$
\begin{aligned}
& V B=V(Q)-V(Q \mid F)= \\
& \sum_{q} P(q)\left[X_{q} \sum_{q} P(q) X_{Q}\right]^{2} \sum_{q} P(q \mid f)\left[X_{q} \sum_{q} P(q \mid f) X_{q}\right]^{2}
\end{aligned}
$$

where $\mathrm{V}$ represents variance; $\mathrm{H}$ represents entropy; $\mathrm{Q}$ represents the target node; $\mathrm{F}$ represents other nodes; $\mathrm{q}$ and $\mathrm{f}$ represent the states of $\mathrm{Q}$ and $\mathrm{F}$ respectively; $\mathrm{X}_{\mathrm{q}}$ is the real value corresponding to $\mathrm{Q}$. In order to facilitate comparison, the mutual information and belief variance are normalized to the range of $0 \sim 100 \%$ to obtain the mutual information ratio and belief variance ratio.

\section{Structure of the Bayesian network for irrigation water use in the CPEC}

A Bayesian network for irrigation water use in the CPEC was established, and its general structure is shown in Fig. 7. It is mainly composed of four modules: (1) water resources module, which reflects the changes of climate change and human activities on available water resources, including precipitation, agricultural water and other indicators; (2) grain module, which expresses the impact of changes in water resources, planting methods and other factors on grain and its economic benefits, including indicators such as grain yield, planting structure and agricultural output value; (3) "water-food" security module, which reflects the impact of changes in water resources and food system on human health, including indicators such as the proportion of people with safe drinking water and malnourished people; and (4) irrigation module, which expresses the impact of climate change and irrigation mode on irrigation water, including effective precipitation, IR and other indicators.

This study utilized the Netica software which had been widely used ${ }^{78}$ to implement a Bayesian network. The expectation maximization algorithm (EM) built in the Netica finds the probability distribution with the highest possibility through a series of step-by-step iterations based on the given data. The distribution can be further used to estimate the dataset analysis with incomplete or missing observations ${ }^{79}$. At the same time, the data were discretized to reduce the amount of calculation of the joint probability distribution in this study. In particular, the data were divided into high, medium, and low levels according to the actual conditions of each variable in the study area. This has been done by using the natural breakpoint method in the Netica to obtain the state classification of node data (Supplementary Table S2).

\section{Declarations}

Acknowledgements: The research is supported by the National Natural Science Foundation of China (52161145102). We would like to thank Editage (www.editage.cn) for English language editing. We are also thankful to anonymous reviewers for improving manuscript through their valuable comments and suggestions.

Author contributions statement :Yaqi Li conceived the idea of the study and designed research, wrote the paper, discussed the results and revised the manuscript; Yaning Chen and Weili Duan conceived the idea of the study and designed research, discussed the results and revised the manuscript; involved in funding acquisition, resources and supervision; Mengzhu Cao collected basic data together and revised the manuscript; Jingxiu Qin analyzed the partial data, discussed the results and revised the manuscript.

Data availability statement: The datasets generated and/or analysed during the current study are not publicly available due the data also forms part of an ongoing study but are available from the corresponding author on reasonable request. 
Competing Interests Statement: All authors have no conflicts of interests to declare.

\section{References}

1. Akber, A. China Pakistan Economic Corridor (CPEC): Prospects and challenges for regional integeration. Arts Soc. Sci. J. 7(1), 1-15 (2015).

2. Hussain, Y., et al. Performance of $\mathrm{CMORPH}, \mathrm{TMPA}$, and PERSIANN rainfall datasets over plain, mountainous, and glacial regions of Pakistan. Theor. Appl. Climatol. 131(3), 1119-1132 (2018).

3. Azam, A. \& Shafique, M. Agriculture in Pakistan and its Impact on Economy. A Review. Inter. J. Adv. Sci. Technol 103, 47-60 (2017).

4. Bhatti, A. M., Suttinon, P. \& Nasu, S. Agriculture water demand management in Pakistan: a review and perspective. Society for Social Management Systems (SSMS) 9, 1-7 (2009).

5. Howells, M. et al. Integrated analysis of climate change, land-use, energy and water strategies. Nat. Clim. Chang., 3(7), 621-626 (2013).

6. Naheed, G.\& Rasul, G. Projections of crop water requirement in Pakistan under global warming. Pak. J. Meteorol. 7, 4551 (2010).

7. Elliott, J. et al. Constraints and potentials of future irrigation water availability on agricultural production under climate change. Proc. Natl. Acad. Sci. 111(9), 3239-3244 (2014).

8. Hargreaves, G. H. \& Samani, Z. A. Reference crop evapotranspiration from temperature. Appl. Eng. Agric. 1, 96-99 (1985).

9. Syperreck, V. L. G., Klosowski, E. S., Greco, M.\& Furlanetto, C. Avaliação de desempenho de métodos para estimativas de evapotranspiração de referência para a região de Palotina, Estado do Paraná. Acta Sci.Agron. 30, 603-609 (2008).

10. Borges, A. C.\& Mendiondo, E. M. Comparação entre equações empíricas para estimativa da evapotranspiração de referência na Bacia do Rio Jacupiranga. Rev. Bras.Eng.Agr.Amb. 11, 293-300 (2007).

11. Maeda, E. E., Wiberg,D. A.\& Pellikka, P. K. Estimating reference evapotranspiration using remote sensing and empirical models in a region with limited ground data availability in Kenya. Appl. Geogr.,31, 251-258 (2011).

12. Er-Raki, S. et al. Assessment of reference evapotranspiration methods in semi-arid regions: can weather forecast data be used as alternate of ground meteorological parameters?. J. Arid. Environ. 74, 1587-1596 (2010).

13. López-Urrea, R., de Santa Olalla, F. M., Fabeiro, C. \& Moratalla, A. Testing evapotranspiration equations using lysimeter observations in a semiarid climate, Agric. Water Manag., 85, 15-26 (2006).

14. Wei, B. Applicability evaluation of ET_0 calculation method in Cheerchen River Basin, Xinjiang. Water Saving Irrigation 11,36-38 + 43 (2016) (in Chinese).

15. Nazeer, M. Comparison of different methods for estimation of potential evapotranspiration. Nucleus 47, 41-46 (2010).

16. Pagano, A., Giordano, R., Portoghese, I., Fratino, U. \& Vurro, M. A Bayesian vulnerability assessment tool for drinking water mains under extreme events. Nat. Hazards 74(3), 2193-2227 (2014).

17. Death, R. G., Death, F., Stubbington, R., Joy, M. K. \& van den Belt, M. How good are Bayesian belief networks for environmental management? A test with data from an agricultural river catchment. Freshw.Biol. 60, 2297-2309 (2015).

18. Nash, D. \& Hannah, M. Using Monte-Carlo simulations and Bayesian Networks to quantify and demonstrate the impact of fertiliser best management practices. Environ. Modell. Softw. 26, 1079-1088 (2011).

19. Fienen, M. N., Masterson, J. P., Plant, N. G., Gutierrez, B. T.\& Thieler, E. R. Bridging groundwater models and decision support with a Bayesian network. Water Resour. Res. 49, 6459-6473 (2013).

20. Giordano, R., D'Agostino, D., Apollonio, C., Lamaddalena, N.\& Vurro, M. Bayesian belief network to support conflict analysis for groundwater protection: the case of the Apulia region. J. Environ. Manage. 115, 136-146 (2013). 
21. Mamitimin, Y., Feike, T. \& Doluschitz, R. Bayesian network modeling to improve water pricing practices in northwest China. Water 7, 5617-5637 (2015).

22. Quinn, J. M., Monaghan, R. M., Bidwell, V. J. \& Harris, S. R. A Bayesian Belief Network approach to evaluating complex effects of irrigation-driven agricultural intensification scenarios on future aquatic environmental and economic values in a New Zealand catchment. Mar. Freshw. Res. 64, 460-474 (2013).

23. Wang, M., Yang, Q., Zheng, J.H.\& Liu, Z.H. Spatial and temporal distribution of water requirement of cotton in Xinjiang from 1963 to 2012. Acta Ecologica Sinica 36, 4122-4130 (2016) (in Chinese).

24. Naheed, G.\& Rasul, G. Recent water requirement of cotton crop in Pakistan. Pak. J. Meteorol. 6, 75-84 (2010).

25. Naheed, G.\& Mahmood, A. Water requirement of wheat crop in Pakistan. Pak. J. Meteorol. 6, 89-97 (2009).

26. Peña-Arancibia, J.L., Stewart, J.P. \& Kirby, J.M. Water balance trends in irrigated canal commands and its implications for sustainable water management in Pakistan: Evidence from 1981 to 2012. Agric. Water Manag. 245, 106648 (2021).

27. Zaidi, A.Z., Khan, N.A., Lashari, B.K., Laghari, F. A. \& Panhwar, V. Agricultural Water balance Study in Sindh (Pakistan) 2 using Satellite-derived Actual Evapotranspiration 3. Remote Sens. 30, 31 (2020).

28. Ahmad, M. \& Farooq, U. The state of food security in Pakistan: Future challenges and coping strategies. Pak. Dev. Rev. 49, 903-923 (2010).

29. Abid, M., Schneider, U. A. \& Scheffran, J. Adaptation to climate change and its impacts on food productivity and crop income: Perspectives of farmers in rural Pakistan. J. Rural Stud. 47, 254-266 (2016).

30. Blunden, J. \& Arndt, D. S. State of the climate in 2011. Bull. Am. Meteorol. Soc. 93, S1-S282 (2012).

31. Khan, A. N. Analysis of 2010-flood causes, nature and magnitude in the Khyber Pakhtunkhwa, Pakistan. Nat. Hazards 66, 887-904 (2013).

32. Butt, A., Shabbir, R., Ahmad, S. S. \& Aziz, N. Land use change mapping and analysis using Remote Sensing and GIS: A case study of Simly watershed, Islamabad, Pakistan. Egypt J. Remote Sens. Space Sci. 18, 251-259 (2015).

33. Mahmood, N. et al. Wheat yield response to input and socioeconomic factors under changing climate: Evidence from rainfed environments of Pakistan. Sci. Total Environ. 688, 1275-1285 (2019).

34. Shen, Y., Li, S., Chen, Y., Qi, Y. \& Zhang, S. Estimation of regional irrigation water requirement and water supply risk in the arid region of Northwestern China 1989-2010. Agric. Water Manag. 128, 55-64 (2013).

35. Bashir, M. K., Schilizzi, S. \& Pandit, R. Regional sensitivity of rural household food security: The case of Punjab, Pakistan. J. Anim. Plant Sci. 23(4),1200-1206 (2013).

36. Yang, Z., Tang,J. \& Yu, X. Xinjiang Cotton Industy Present and Countermeasures Research. Research of Agricultural Modernization 196(03),298-302 (2013)(in Chinese).

37. Zhang, Q., Sun, P., Singh, V. P., \& Chen, X. Spatial-temporal precipitation changes (1956-2000) and their implications for agriculture in China. Glob. Planet. Change 82, 86-95 (2012).

38. Leng, G.Y. \& Tang, Q.H. Modeling the impacts of future climate change on irrigation over China: sensitivity to adjusted projections. J. Hydro meteorol. 15, 2085-2103 (2014)

39. Cong, Z.T., Yao, B.Z.\& Ni, G.H. Crop water demand in China under the SRA1B emissions scenario Adv. Water Sci. 22, 38$43(2011)$

40. Zeng, R. et al. Assessing the effects of precipitation and irrigation on winter wheat yield and water productivity in North China Plain. Agric. Water Manag. 256, 107063 (2021).

41. Ullah, S., You, Q., Ullah, W.\& Ali, A. Observed changes in precipitation in China-Pakistan economic corridor during 19802016. Atmos. Res. 210, 1-14 (2018).

42. Zhang, Y., Wang, Y., \& Niu, H. Effects of temperature, precipitation and carbon dioxide concentrations on the requirements for crop irrigation water in China under future climate scenarios. Sci. Total Environ. 656, 373-387 (2019).

43. Deryng, D.et al. Rosenzweig Regional disparities in the beneficial effects of rising CO2 concentrations on crop water productivity. Nat. Clim. Chang. 6, 786-790 (2016).

Page $15 / 23$ 
44. Winter, J. M.et al.. Representing water scarcity in future agricultural assessments. Anthropocene 18, 15-26 (2017).

45. Ficklin, D., Luedeling, E.\& Zhang, M. Sensitivity of groundwater recharge under irrigated agriculture to changes in climate, CO2 concentrations and canopy structure Agric. Water Manag. 97, 1039-1050 (2010).

46. Fader, M., Shi, S., Bloh, W. V., Bondeau, A., \& Cramer, W.. Mediterranean irrigation under climate change: more efficient irrigation needed to compensate for increases in irrigation water requirements. Hydrol. Earth Syst. Sci. 20(2), 953-973 (2016).

47. Baloch, S.M. Water crisis: Why is Pakistan running dry. https://www.dw.com/en/water-crisis-why-is-pakistan-runningdry/a-44110280 (2018).

48. Ranjan, A. Inter-Provincial water sharing conflicts in Pakistan. Pak. A J. Pak. Stud. 4, 102-122 (2012).

49. Guo, Y. \& Shen, Y. Agricultural water supply/demand changes under projected future climate change in the arid region of northwestern China. J. Hydrol. 540, 257-273 (2016).

50. Haider, S. \& Ullah, K. Projected crop water requirement over agro-climatically diversified region of Pakistan. Agric. For. Meteorol. 281, 107824 (2020).

51. Rehman, A., Chandio, A. A., Hussain, I. \& Luan J. Fertilizer consumption, water availability and credit distribution: Major factors affecting agricultural productivity in Pakistan. J. Saudi Soc. Agric. Sci.18(3), 269-274 (2019).

52. Koondhar, M. A.et al. Asymmetric causality among carbon emission from agriculture, energy consumption, fertilizer, and cereal food production-a nonlinear analysis for Pakistan. Sustain. Energy Technol. Assess. 45,101099 (2021).

53. Ozturk, I. The dynamic relationship between agricultural sustainability and food-energy-water poverty in a panel of selected Sub-Saharan African Countries. Energy policy. 107, 289-299 (2017).

54. Rehman, A.et al. Another outlook to sector-level energy consumption in Pakistan from dominant energy sources and correlation with economic growth. Environ. Sci. Pollut. Res. 28, 33735-33750 (2020).

55. Shah, M., Ara, J., Muhammad, S., Khan, S. \& Tariq, S. Health risk assessment via surface water and sub-surface water consumption in the mafic and ultramafic terrain, Mohmand agency, northern Pakistan. J. Geochem. Explor. 118, 60-67 (2012).

56. Qureshi, A. S., McCornick, P. G., Qadir, M. \& Aslam, Z. Managing salinity and waterlogging in the Indus Basin of Pakistan. Agric. Water Manag. 95, 1-10 (2008).

57. Aslam, M. Agricultural productivity current scenario, constraints and future prospects in Pakistan. Sarhad J. Agric. Sci. 32, 289-303 (2016).

58. Zulfiqar, F. \& Thapa, G. B. Agricultural sustainability assessment at provincial level in Pakistan. Land Use Pol. 68, 492502 (2017).

59. Endo, A., Tsurita, I., Burnett, K. \& Orencio, P. M. A review of the current state of research on the water, energy, and food nexus. J. Hydrol. Reg. Stud. 11, 20-30 (2017).

60. Huang, G.\& Loucks, D. P. An inexact two-stage stochastic programming model for water resources management under uncertainty. Civil Eng. Syst. 17, 95-118 (2000).

61. Fischer, E.M., Seneviratne, S. I., Lüthi, D.\& Schär, C. Contribution of land-atmosphere coupling to recent European summer heat waves. Geophys. Res. Lett. 34(6), L06707 (2007).

62. Yang, J. et al. Projection of 21st century irrigation water requirement across the Lower Mississippi Alluvial Valley. Agric. Water Manag. 217, 60-72 (2019).

63. Li, Z., Fang, G., Chen, Y., Duan, W. \& Mukanov, Y. Agricultural water demands in Central Asia under $1.5^{\circ} \mathrm{C}$ and $2.0^{\circ} \mathrm{C}$ global warming. Agric. Water Manag. 231,106020 (2020).

64. Qureshi, M.E., Whitten,S.m., Mainuddin,M., Marvanek,S. \& Elmahdi,A. A bio-physical and economic model of agriculture and water in the Murray-Darling Basin, Autralia. Environ. Model. Softw. 41, 98-106 (2013).

65. Rasul, G. \& Mahmood, A. Performance evaluation of different methods for estimation of evapotranspiration in Pakistan's climate. Pak. J. Meteorol. 5, 25-36 (2009).

Page $16 / 23$ 
66. Shi, H.et al. Coupling the water-energy-food-ecology nexus into a Bayesian network for water resources analysis and management in the Syr Darya River basin. J. Hydrol. 581, 124387 (2020).

67. Iqbal, M. F.\& Athar, H. Validation of satellite based precipitation over diverse topography of Pakistan. Atmos.Res. 201, 247-260 (2018).

68. Chen, J., Tao, H.\& Liu, J. A daily meteorological dataset of the China-Pakistan Economic Corridor from 1961 to 2015. Science Data Bank 6, 229-238 (2021) (in Chinese).

69. Imran, A. \& Saleh, S. Crop Development in Central Punjab, Faisalabad (2017-2018). 25 (Faisalabad, Pakistan, Ayub Agriculture Research Institute, 2008).

70. Kahlown, M.\& Ashraf, M. Effect of shallow groundwater table on crop water requirements and crop yields. Agric. Water Manag. 76, 24-35 (2005).

71. Tariq, M. \& Iqbal, H. Maize in Pakistan-an overview. Agric. Nat. Resour. 44, 757-763 (2010).

72. Rost, S. et al. Agricultural green and blue water consumption and its influence on the global water system. Water Resour. Res. 44, W09405 (2008).

73. Li,Y.; et al. Estimation of regional irrigation water requirements and water balance in Xinjiang, China during 1995-2017. PeerJ 8, e8243 (2020).

74. Cain, K., Oakhill, J. V., Barnes, M. A. \& Bryant, P. E. Comprehension skill, inference-making ability, and their relation to knowledge. Mem.Cognit. 29, 850-859 (2001).

75. Marcot, B. G. Metrics for evaluating performance and uncertainty of Bayesian network models. Ecol.Modell. 230, 50-62 (2012).

76. Pollino, C. A., Woodberry, O., Nicholson, A., Korb, K. \& Hart, B. T. Parameterisation and evaluation of a Bayesian network for use in an ecological risk assessment. Environ. Modell. Softw. 2007, 22, 1140-1152.

77. Barton, D., Saloranta, T., Moe, S., Eggestad, H.\& Kuikka, S. Bayesian belief networks as a meta-modelling tool in integrated river basin management-Pros and cons in evaluating nutrient abatement decisions under uncertainty in a Norwegian river basin. Ecol. Econ. 66, 91-104 (2008).

78. Uusitalo, L. Advantages and challenges of Bayesian networks in environmental modelling, Ecol. Modell. 203, 312-318 (2007).

79. Poppenborg, P. \& Koellner, T. A Bayesian network approach to model farmers' crop choice using socio-psychological measurements of expected benefits of ecosystem services. Environ. Modell. Softw. 57, 227-234 (2014).

\section{Figures}




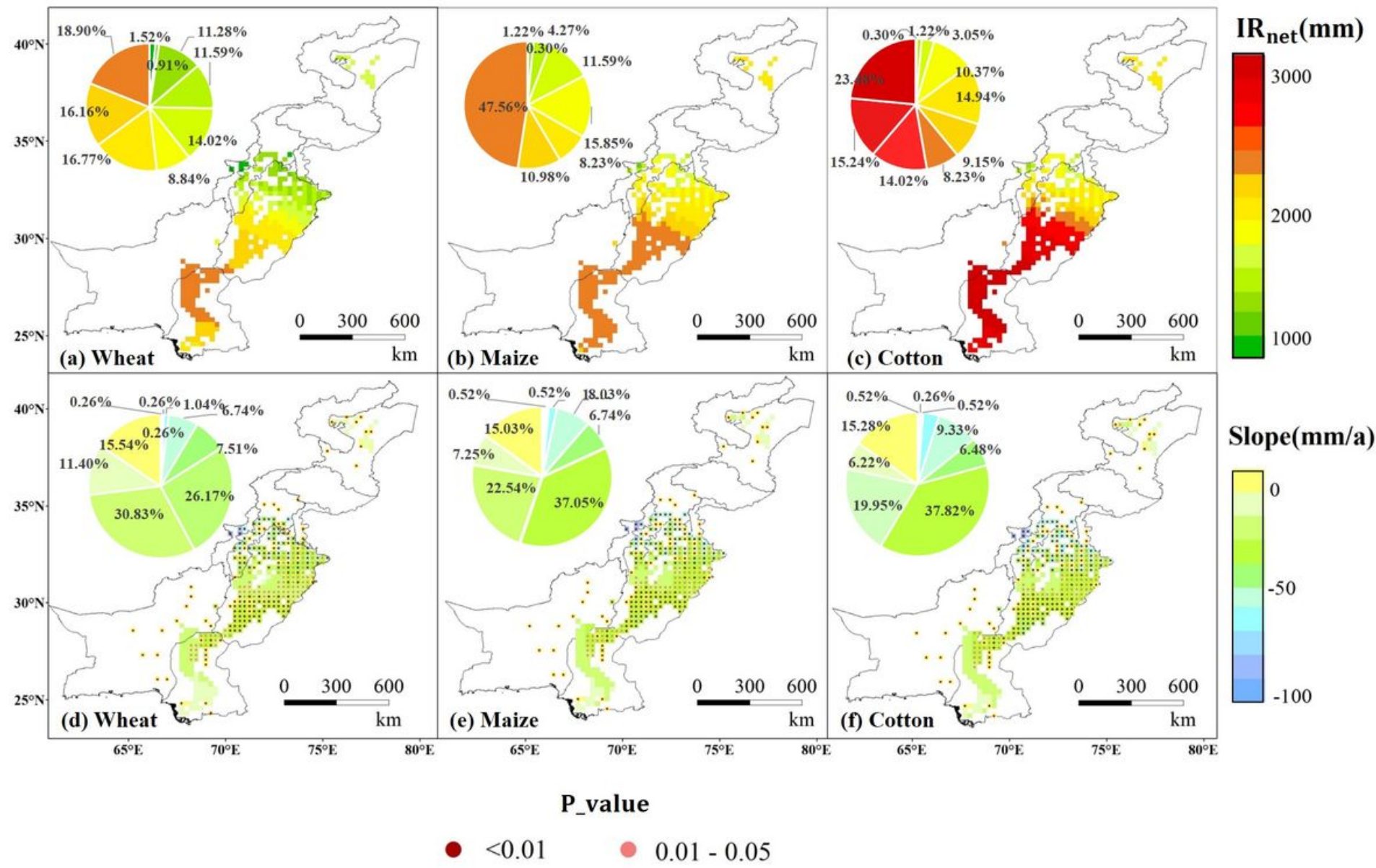

Figure 1

Annual average net irrigation water requirement $\left(I_{R_{\text {net }}}\right)(a)(b)(c)$ and spatial distribution, trend and significance (d) (e) (f) for wheat, maize, cotton in irrigated areas of the China-Pakistan Economic Corridor (CPEC) from 2000 to 2015. 


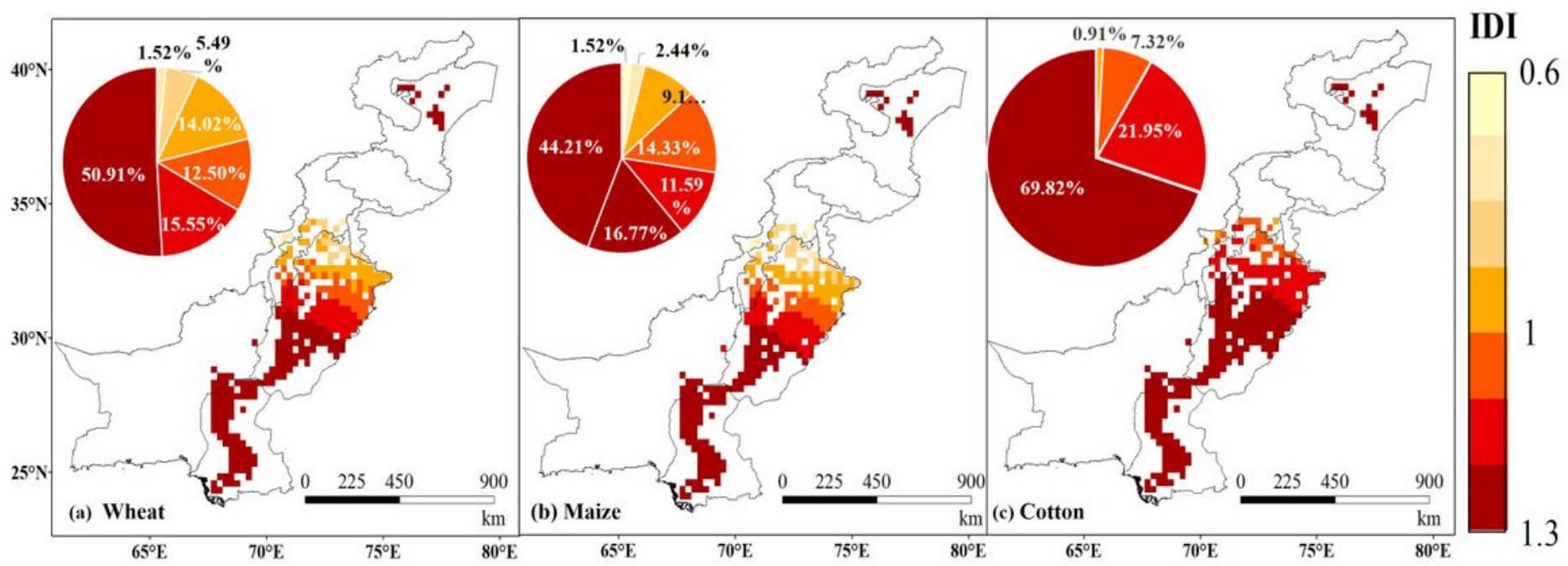

Figure 2

Spatial distribution of average annual IDI of wheat (a), maize (b) and cotton (c) in the Irrigated region of the China-Pakistan Economic Corridor (CPEC) from 2000 to 2015.

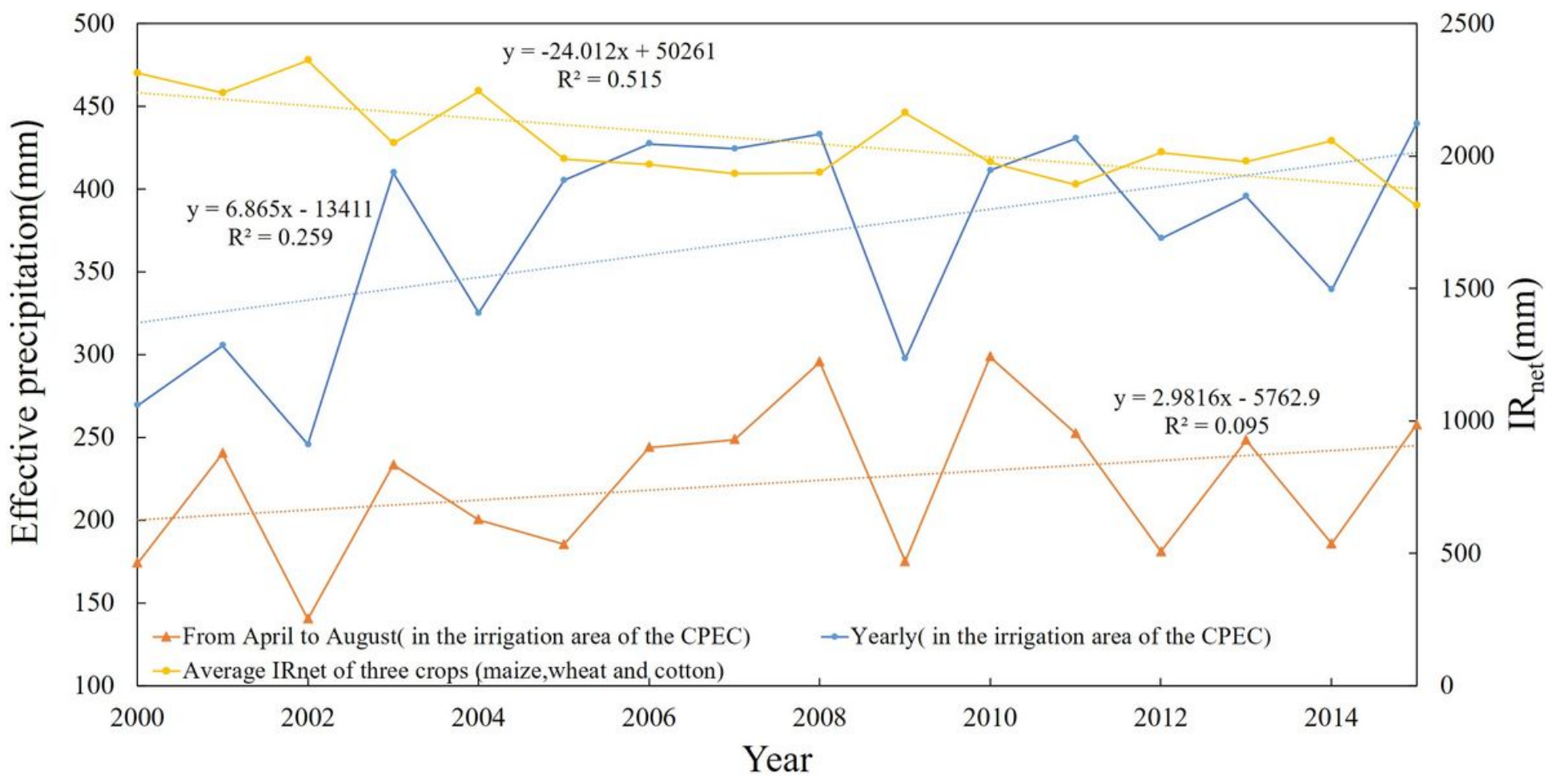

Figure 3 
Inter-annual variation trends of effective precipitation $\left(P_{e}\right)$ and average net irrigation water requirement ( $\left(R_{\text {net }}\right)$ of three crops (maize, wheat, and cotton) in irrigated areas of the China-Pakistan Economic Corridor (CPEC) from 2000 to 2015.

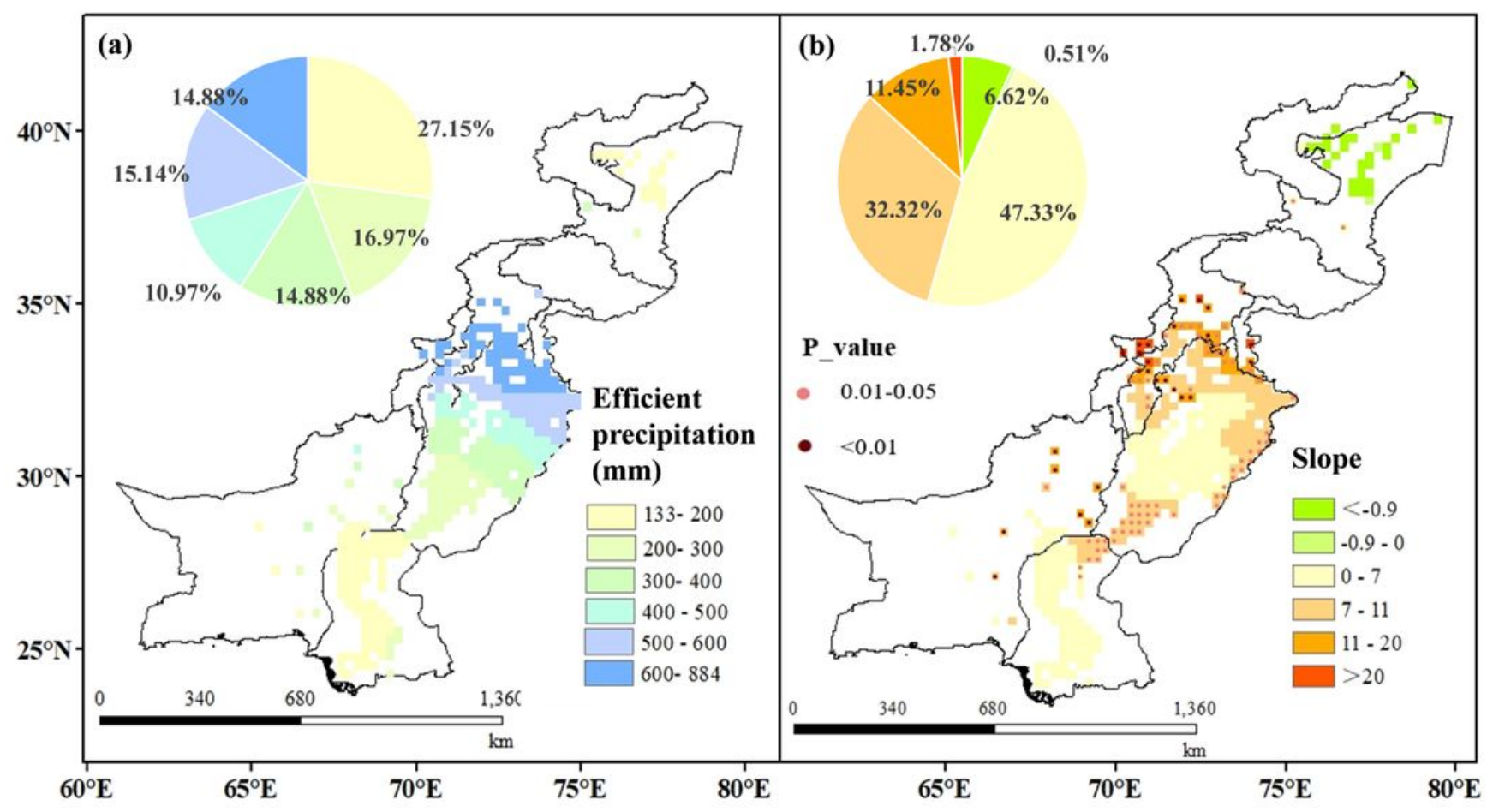

Figure 4

Spatial distribution (a), trend and significance $(b)$ of annual average effective precipitation $\left(P_{e}\right)$ in irrigated areas of the China-Pakistan Economic Corridor (CPEC) from 2000 to 2015. 


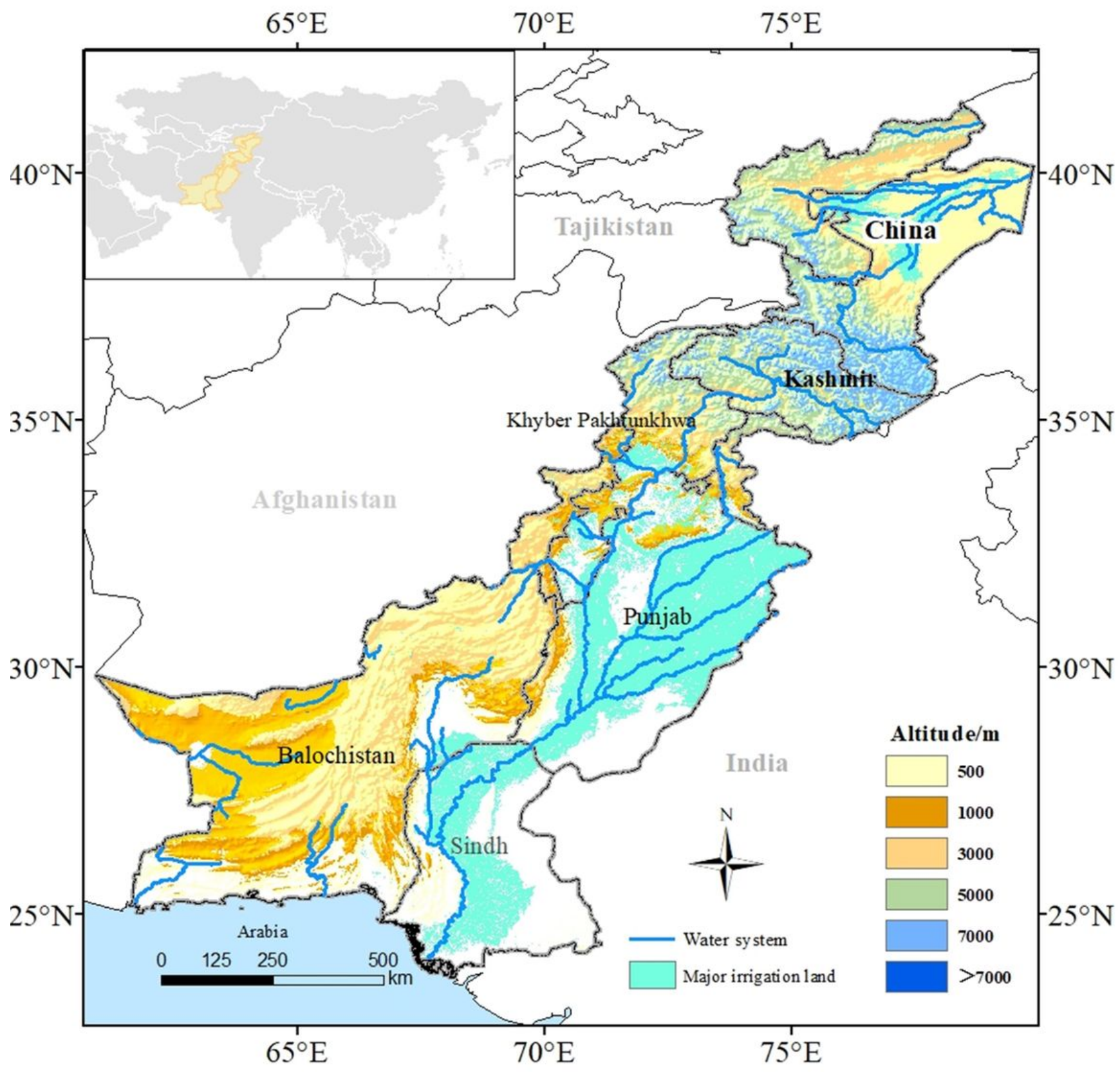

Figure 5

Map of the China-Pakistan Economic Corridor (CPEC) study area 


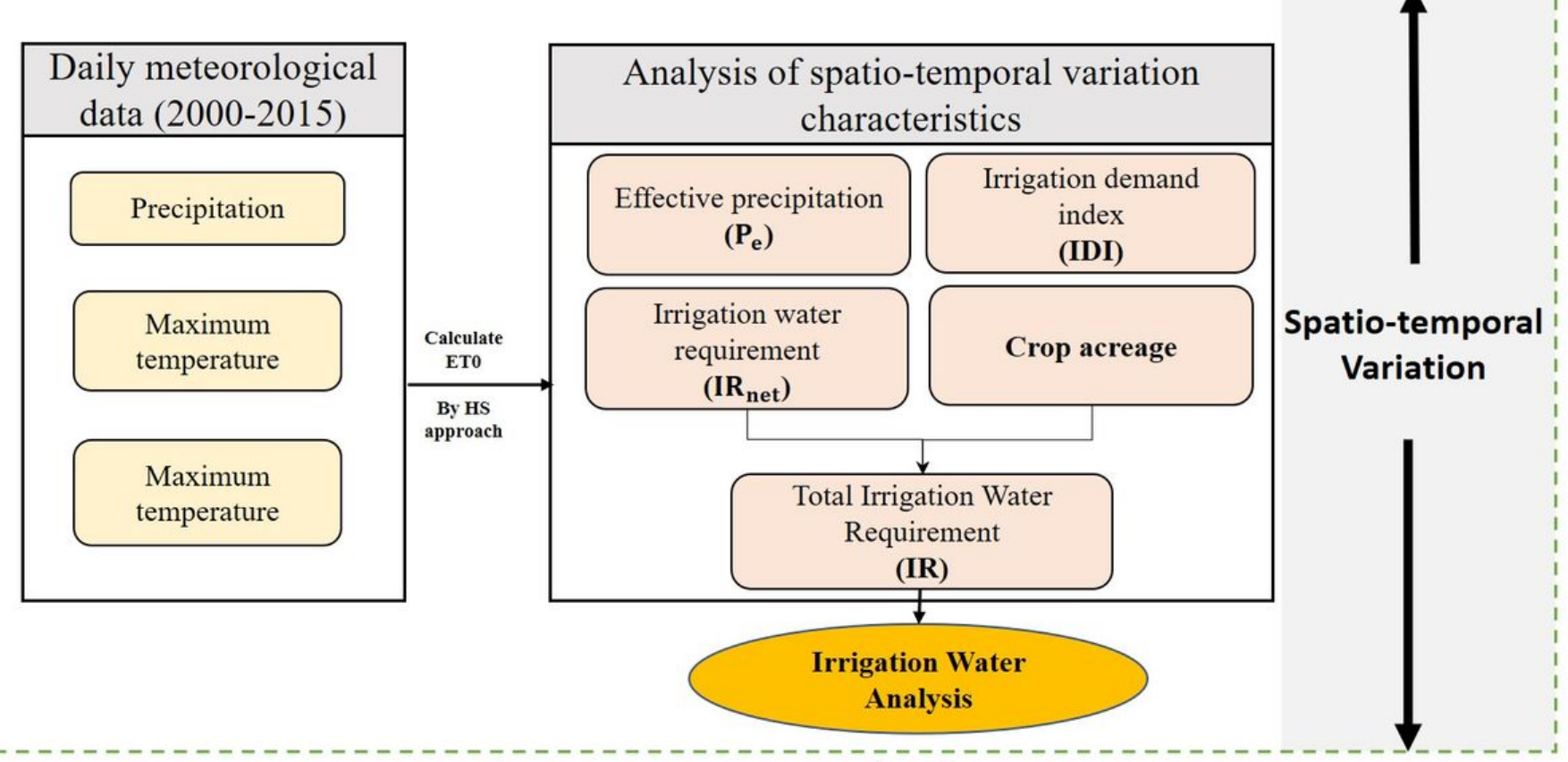

IR and crop acreage as important nodes

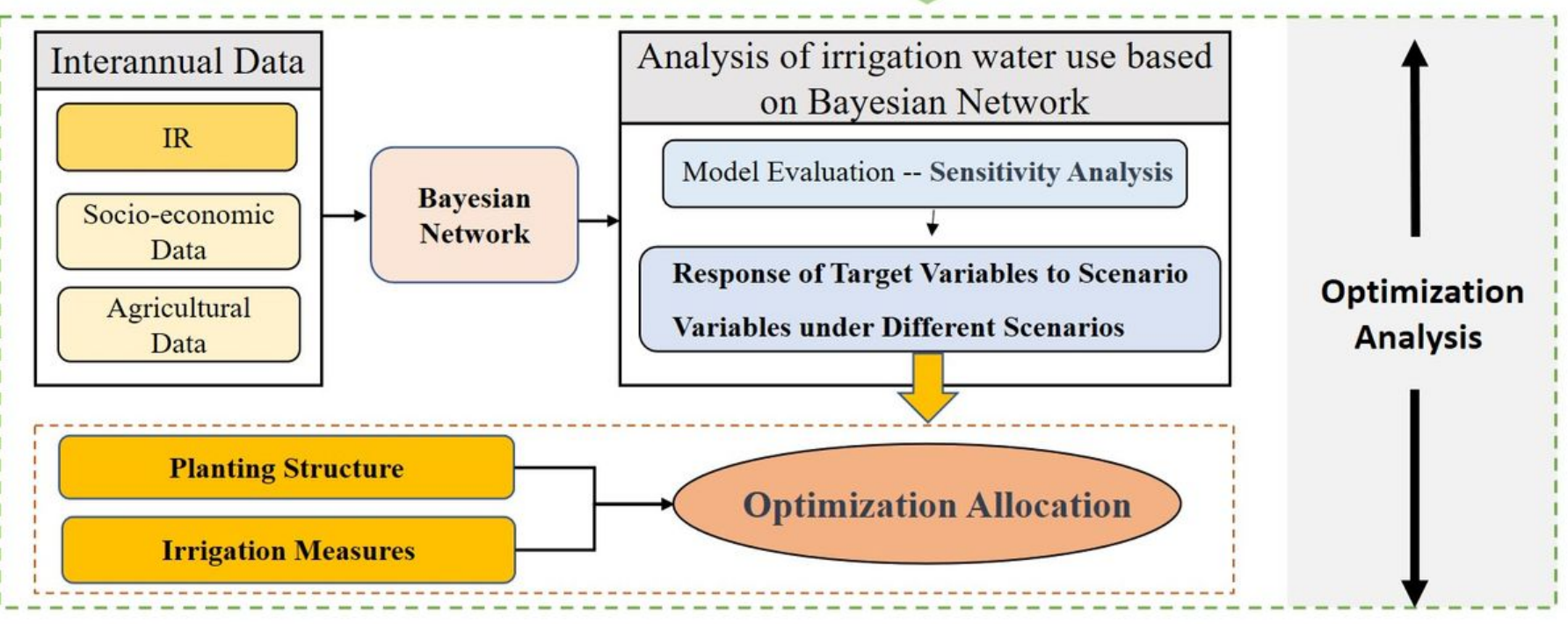

Figure 6

Research approach and technical route. 


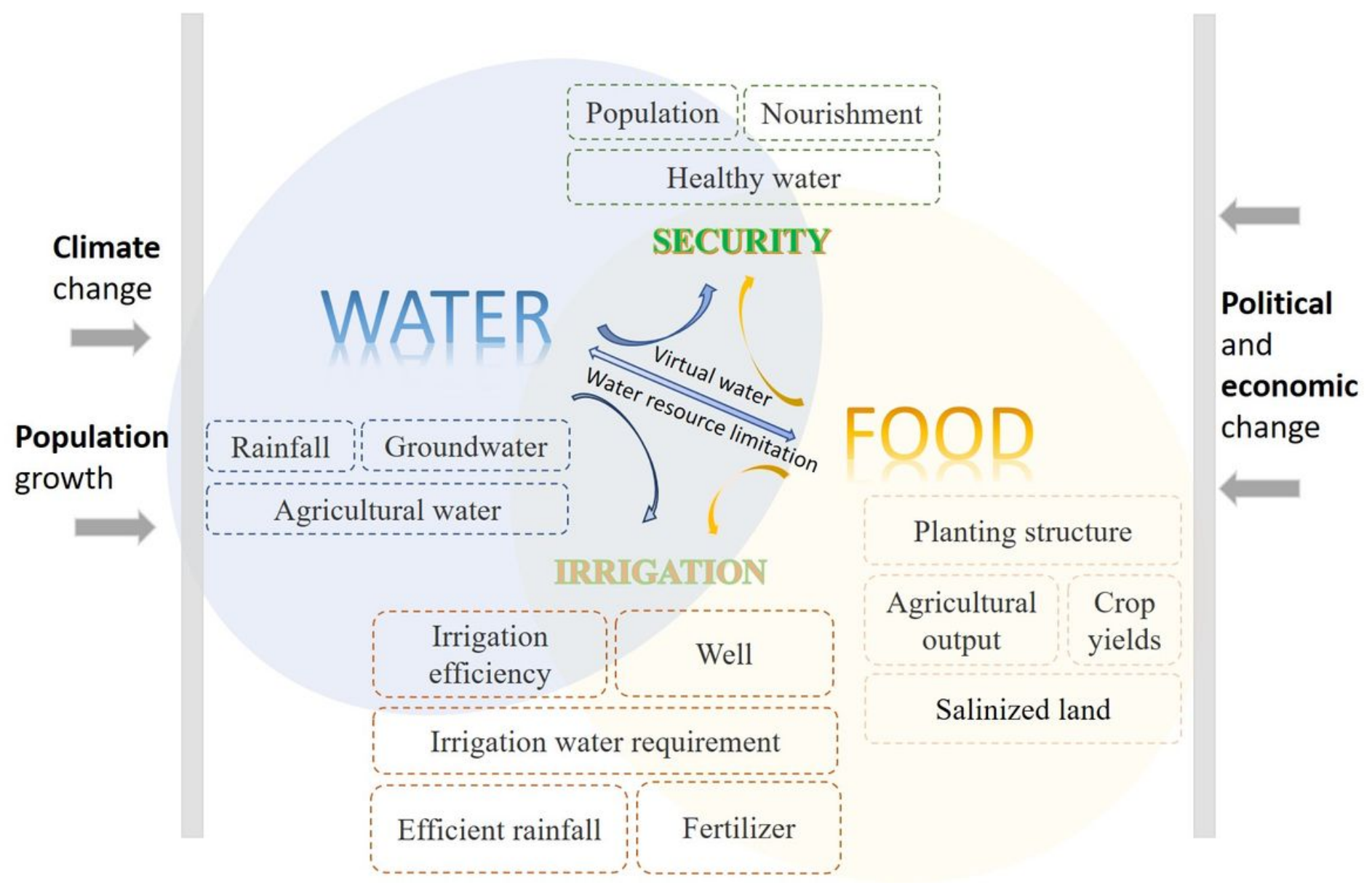

Figure 7

Schematic diagram of Bayesian network structure.

\section{Supplementary Files}

This is a list of supplementary files associated with this preprint. Click to download.

- Additionallnformation.docx 